\title{
O mercado do melado da agroindústria familiar de Santo Antônio da Patrulha, RS
}

\author{
Ana Mônica Fitz de Oliveira" \\ Matheus Shelton Ramos Miguel ${ }^{* * *}$ \\ Alex Leonardi****
}

Resumo

Santo Antônio da Patrulha, no estado do Rio Grande do Sul, é um município com cerca de 42.220 habitantes. O cultivo da cana-de-açúcar, mais especificamente a produção do melado, diversificou-se em variados produtos obtidos a partir desse, os quais levaram o município a ser reconhecido por sua produção de rapadura. A partir dessa realidade, o objetivo da pesquisa é analisar a estrutura de mercado do melado da agroindústria familiar de forma a contribuir com o desenvolvimento do setor e da região. Os dados foram analisados a partir do índice Herfindhal-Hirschmann Index. O índice encontrado foi de 880.773 , o que significa que o mercado não está concentrado, indicando que há competição entre os produtores. Isso leva a implicações nas condições de venda desses produtos em Santo Antônio da Patrulha.

Palavras-chave: Concentração de mercado. Agroindústria familiar. Melado.

* Graduada em Engenharia Agroindustrial Agroquímica pela Universidade Federal do Rio Grande (2018). Mestranda em Administração pela Universidade Federal do Rio Grande na linha de pesquisa de Tecnologias Gerenciais. E-mail: ana.monica89@hotmail.com

** Filiação: Bolsista PIBIC/CNPq e Graduando em Engenharia Agroindustrial: Agroquímica na FURG, Campus Santo Antônio da Patrulha - RS. E-mail: sheltonmiguel.02@gmail.com

*** Professor Adjunto de Economia nas Engenharias Agroindustriais na Universidade Federal do Rio Grande, Campus Santo Antônio da Patrulha, Rio Grande do Sul, Brasil. E-mail: alleo123@gmail. com 


\section{Introdução}

Santo Antônio da Patrulha é, reconhecidamente, importante produtor de derivados da cana-de-açúcar, os quais estão entre suas principais atividades econômicas e fazem parte não apenas de uma cadeia produtiva, mas de todo um sistema, formando uma estrutura de mercado que deve ser conhecida e analisada visando seu crescimento, para ajudar na promoção do desenvolvimento local. A busca por esse desenvolvimento, então, passa por um conjunto de estudos capazes de identificar e indicar as ações necessárias nesse sentido.

A análise da estrutura de mercado de melado da agroindústria familiar da cana-de-açúcar, bem como a concentração desse setor, é uma forma de identificar como a indústria está distribuída em termos de produção e participação no mercado. Além disso, permite uma clara noção das articulações econômicas referentes à competitividade.

Para Bain (1968), um dos precursores do estudo da organização industrial, essa análise em um país é o exame do comportamento do conjunto de empresas que competem entre si numa mesma indústria, sejam elas grandes ou pequenas. Nessa perspectiva, conforme Kupfer e Hasenclever (2002), o entrelaçamento de cadeias produtivas é comum, sendo que muitas se repartem e outras se juntam, e não há por que presumir que a teia de cadeias produtivas se espalhe, de maneira uniforme, sobre a estrutura econômica.

Por isso, entre os aspectos que podem contribuir para o desenvolvimento local, através da geração de emprego, renda e melhor nível de bem-estar social, a partir da análise da estrutura e concentração não apenas do melado, mas dos demais derivados da agroindústria da cana-de-açúcar, no município de Santo Antônio da Patrulha, estão a apresentação e a definição de estratégias competitivas para inserção em outros mercados regionais, a redução de custos como forma de tornar essa indústria mais eficiente, além das possibilidades de se beneficiar de economias de escala e integração vertical, da diferenciação e do desenvolvimento de produtos, preços, entre outros.

A partir disso, esta pesquisa tem como principal objetivo analisar a estrutura de mercado do melado, na agroindústria da cana-de-açúcar, no município de Santo Antônio da Patrulha, para contribuir com aspectos relevantes para o crescimento do setor e, em consequência, para o desenvolvimento da região. Especificamente, busca-se medir o índice de concentração, a partir dos dados da área plantada e da 
produção de melado, que nesse município é o principal derivado dessa agroindústria, além de tentar compreender o funcionamento do mercado, da comercialização e do preço desse produto. Esses objetivos serão alcançados por meio de entrevistas abertas com os produtores familiares e com a Empresa de Assistência Técnica e Extensão Rural do Estado do Rio Grande do Sul (Emater/RS), que presta assistência, e, também, utilizando a análise estatística para se obter o índice de concentração Herfindhal-Hirschman Index (HHI), que considera a produção de cada agroindústria, sendo descrito na seção que trata sobre o método.

Outro aspecto que surge a partir do estudo dessa agroindústria familiar e que deve ser considerado é a formação de uma organização informal dos produtores de melado, o Programa Puro Engenho, coordenado pela Emater/RS de Santo Antônio da Patrulha, principalmente, que tem como principais objetivos a assistência técnica conjunta, no sentido de adequar as agroindústrias às especificidades técnicas, além de auxiliar na elaboração de projetos e de um melhor planejamento e controle da produção.

Dessa forma, o trabalho está estruturado, a partir dessa introdução, da seguinte maneira: na segunda seção, é apresentado o referencial teórico acerca da concentração de mercado e caracterização regional, bem como uma descrição do Programa Puro Engenho; na terceira seção, é apresentado o método; na quarta, os resultados; e, por fim, as considerações finais.

\section{Referencial teórico}

O objetivo deste referencial é apresentar, inicialmente, aspectos teóricos e conceituais relacionados à concentração dos mercados. Em seguida, caracterizar a região, destacando o município de Santo Antônio da Patrulha e a produção do melado, entre os derivados da cana-de-açúcar, bem como descrever o papel do Programa Puro Engenho, como uma forma de organização dos produtores.

\subsection{Concentração de mercado}

É fundamental analisar e quantificar a concentração dos mercados, para que se possa avaliar a estrutura de mercado, identificando, a partir daí, os pontos relevantes da sua natureza, como a competitividade e os demais elementos que 
interferem na conduta e no desempenho das empresas, sejam elas de grande porte ou familiares, como é o caso desse trabalho. Analisar a concentração de mercado parte do pressuposto de entender como uma indústria está distribuída quanto à sua produção e à participação por meio das suas firmas num dado mercado, além das suas capacidades de determinar preço e influenciar nas decisões da cadeia produtiva.

De acordo com George e Joll (1983), a concentração refere-se à distribuição conforme o tamanho das firmas que vendem um dado produto, constituindo uma dimensão de grande significância da estrutura de mercado, pois desempenha, desse modo, um importante papel no desempenho e comportamento da empresa. Já, para Labini (1980), a concentração é um processo voltado para a busca de uma crescente eficiência técnica e econômica.

Conforme afirma Bain (1968), a estrutura de mercado faz referência às características da organização que determinam as relações entre os agentes, constituindo, então, uma parte importante do ambiente competitivo das firmas, pelo motivo de exercerem influência sobre o padrão de concorrência. Dessa forma, as características de estrutura de mercado interferem estrategicamente na natureza da competição e determinação de preços dentro do mercado.

Além disso, Porter (1993) afirma que a análise estrutural das indústrias deve ser examinada pela ótica da estratégia competitiva, a qual deve nascer de um conhecimento detalhado da sua estrutura e da maneira pela qual ela se modifica. Possas (1985) considera relevantes os conceitos tradicionais de estrutura de mercado, condições de entrada de possíveis concorrentes, acumulação de lucros, progresso técnico e evolução da estrutura organizacional da firma perante os concorrentes.

Para Possas, Fagundes e Pondé (1998), estrutura de mercado se define como o ambiente em que se inserem os agentes, descrevendo-se a partir do número de firmas, da distribuição de suas quotas de participação, do grau de homogeneidade dos produtos, da proximidade dos substitutos, das condições de entrada e saída, do nível de integração vertical da atividade e das informações de que dispõem os agentes.

Quanto à classificação dos mercados, Farina (2000) seleciona os mercados como competitivos, oligopólios concentrados, oligopólios diferenciados, oligopólios competitivos e monopólios. Nos mercados competitivos, o produto é homogêneo e o mercado é fragmentado, existe uma baixa diferenciação e ausência de barreiras de entrada. Por sua vez, os oligopólios concentrados mantêm a concentração elevada,

Teoria e Evidência Econômica - a. 24, n. 51, p. 269-281, jul./dez. 2018 
o produto é homogêneo e elevadas barreiras técnicas estão presentes. Ainda, nos oligopólios diferenciados, percebe-se concentração elevada, diferenciação no produto e, dessa forma, a existência de barreiras técnicas (FARINA, 2000).

Conforme as distinções feitas por Farina (2000), os oligopólios competitivos passam a existir quando a concentração é alta, os produtos são diferenciados e existem barreiras de diferenciação. Por sua vez, o monopólio é a situação em que apenas uma firma ou um mercado atua pelo motivo das altas economias de escala, situação essa ligada aos fatores como barreiras de entrada, economias de escopo, custos de transação e especificidade dos ativos.

Segundo Souza (1980), o grau de concentração observado em um mercado constitui um indicador da sua estrutura, ou seja, um pequeno valor do grau de concentração é entendido como uma amostra nas proximidades da concorrência perfeita, já se esse valor se mostrar alto, entende-se que existem estruturas oligopolistas nesse mercado.

\subsection{Caracterização local e o Programa Puro Engenho}

O Conselho Regional Metropolitano Delta do Jacuí (Corede Metropolitano Delta do Jacuí), no qual o município de Porto Alegre está incluído, conta com uma população total de 2.558 .885 habitantes e uma área de $5.651,4 \mathrm{~km}^{2}$ (FEE, 2016). Santo Antônio da Patrulha é um dos dez municípios integrantes, contando com uma população de 42.220 habitantes, uma área de $1.049,8 \mathrm{~km}^{2}$, PIB total de $\mathrm{R} \$ 886.392$ e PIB per capita de $\mathrm{R} \$ 21.318,25$.

Para Wandscheer e Bastian (2010), as principais características que se destacam no município são os potenciais agrícolas, principalmente os relacionados ao cultivo da cana-de-açúcar, trazida em 1770 pelos colonizadores portugueses. Com o passar do tempo, a cultura agrícola da cana-de-açúcar expandiu-se de tal modo a tornar-se parte da cultura do município, integrando parte da história e base econômica da região.

Ainda de acordo com Wandscheer e Bastian (2010), inicialmente, o cultivo de cana era voltado principalmente para a produção de cachaça, contudo, ao longo dos anos, os produtos começaram a se diversificar, não mais produzindo apenas cachaça, como também novos produtos que vieram "incrementando" essa cultura, como a rapadura, em suas várias formas conhecidas, "puxa", "massenta", "quebra-queixo", "pé-de-moleque", além de melado e caldo de cana. 
Ao mesmo tempo em que a produção se diversificou, a forma de produzir também foi alterada. No início, o cultivo agrícola e o manejo da cana-de-açúcar eram bastante primitivos, com o passar do tempo, o avanço da tecnologia afetou também o cultivo e a produção, tornando-o um setor industrializado.

De acordo com Ferreira e Barcelos (2006), com essa evolução, viu-se que era necessária uma medida para articular e qualificar a cadeia produtiva, além de ajudar os produtores em suas possíveis dificuldades relacionadas à produção e à comercialização.

Então se iniciou o Programa Puro Engenho, que, segundo informações da Emater/RS de Santo Antônio da Patrulha, visa a uma qualificação, além de atender os produtores com suas dúvidas e dificuldades no âmbito da produção. Esse acompanhamento é realizado pela própria Emater/RS por meio da prestação de assistência técnica aos agricultores no cultivo da cana-de-açúcar, da elaboração de projetos de crédito, de licença ambiental, além de planejamento e elaboração da planta baixa da agroindústria.

Ainda, a colaboração da Emater/RS se destaca desde a participação na capacitação e na elaboração do manual de boas práticas de produção, por meio de treinamentos oferecidos aos produtores, até a identificação de novos mercados para comercialização dos produtos.

Dessa forma, no novo contexto da produção qualificada instituída pelo programa citado, o produto, que antes era comercializado apenas na região, passou a fazer parte da cadeia produtiva de outro produto típico da região, a rapadura, que é produzida por empresas especializadas e já com reconhecimento no mercado regional, sendo comercializada inclusive fora do estado do Rio Grande do Sul, devido à sua qualidade e ao histórico cultural.

Desde a implantação do programa, houve significativas mudanças observadas no setor da produção de melado, como melhores acondicionamento, armazenagem e qualidade do produto, além de maior valor agregado aos produtos comercializados e da regulamentação de contratos de compra do melado com as fábricas da região que o utilizam como matéria-prima. 


\section{Método}

Torna-se importante mensurar a concentração em um mercado para realizar uma análise da sua estrutura, identificando quais são os elementos relevantes dessa configuração e, assim, conhecendo as possibilidades no sentido de ações, sejam elas em termos de negociação de quantidades ou preços, por parte das agroindústrias familiares de melado de Santo Antônio da Patrulha.

Para alcançar o objetivo deste trabalho, os dados foram analisados por intermédio do índice de concentração Herfindhal-Hirschman Index (HHI). O método indica o tamanho e o número das firmas envolvidas em um setor. Sua definição básica é o somatório das parcelas de mercado ao quadrado, esse somatório, quando se aproxima de 10.000, indica um mercado concentrado; quando se aproxima de 0 , indica a existência de um mercado não concentrado (POSSAS et al., 2002).

De acordo com Possas et al. (2002), em um mercado semelhante ao de concorrência perfeita, o valor das participações individuais de mercado é baixo, e o HHI tende a aproximar-se de 0. De outro modo, quando há apenas uma empresa que domina o mercado, sua participação é então de 100\%, correspondendo ao HHI de 10.000, e esse regime aproxima-se então da definição de monopólio.

O HHI considera todas as firmas da indústria, sendo calculado pela Fórmula 1.

$$
\begin{aligned}
& \text { Fórmula (1) } \\
& H H I=\sum_{i=1}^{n} S t=
\end{aligned}
$$

Em que:

$\mathrm{n}$ = número de firmas no mercado;

$\mathrm{Si}$ = participação da i-ésima firma no mercado.

O Conselho Administrativo de Defesa Econômica (CADE) lançou, em julho de 2016, a versão definitiva do Guia para análise de atos de concentração horizontal, e no seu entendimento: (i) os mercados desconcentrados refletem um HHI abaixo de 1.500 pontos; (ii) os mercados moderadamente concentrados refletem um HHI entre 1.500 e 2.500 pontos; e (iii) os mercados altamente concentrados refletem um HHI acima de 2.500 pontos. 


\subsection{Coleta e análise de dados}

Foram entrevistados 15 produtores de agroindústrias familiares que fazem parte do Programa Puro Engenho, com acompanhamento da Emater/RS local, de um total de 16 produtores que produzem melado no município de Santo Antônio da Patrulha. A coleta dos dados ocorreu em 2015, de modo que os dados se referem à safra de 2014.

As informações da Emater/RS de Santo Antônio da Patrulha foram obtidas por meio de entrevistas abertas, já os dados coletados sobre as agroindústrias foram pela utilização de entrevistas fechadas, questionando sobre a área de cana-de-açúcar cultivada na propriedade e a quantidade de melado produzida. No entanto, identificou-se que não há um controle da produção por parte dos produtores, apenas da área plantada. Então, foi utilizada a estimativa de $8.400 \mathrm{Kg}$ de melado/ hectare, informada pela Emater/RS sobre a produtividade por hectare de cana-de-açúcar colhida, conforme a Tabela 1.

Tabela 1 - Dados de produção de agroindústrias de melado no interior de Santo Antônio da Patrulha

\begin{tabular}{ccc}
\hline Produtor & Área cultivada (hectares) & Quantidade de melado produzida $(\mathrm{Kg})$ \\
\hline 1 & 5 & 42.000 \\
2 & 6 & 50.400 \\
3 & 2 & 16.800 \\
4 & 5 & 42.000 \\
5 & 4 & 33.600 \\
6 & 5 & 42.000 \\
7 & 13 & 109.200 \\
8 & 7 & 58.800 \\
9 & 3 & 25.200 \\
10 & 5 & 42.000 \\
11 & 2,3 & 19.320 \\
12 & 10 & 84.000 \\
13 & 2 & 16.800 \\
14 & 5 & 42.000 \\
15 & 3 & 25.200 \\
\hline
\end{tabular}

Fonte: elaboração dos autores com base nos dados coletados, 2015. 


\section{Resultados}

A partir da quantidade de melado produzida, percebe-se a parcela de atuação de cada agroindústria inclusa na pesquisa sobre o mercado de produção de melado da região, partindo para o cálculo e a análise do HHI.

A princípio, foram somadas as quantidades individuais de melado produzidas, a seguir, cada quantidade individual foi dividida por esse total, fornecendo a participação individual de cada uma das agroindústrias no mercado. A próxima etapa foi calcular o somatório dos quadrados dessas participações individuais, para se obter, então, o HHI, conforme mostra a Tabela 2. A partir dos dados da Tabela 2, pode-se determinar a área total de 77,3 hectares de cana-de-açúcar que é cultivada no município de Santo Antônio da Patrulha, resultando em uma produção total de 649.320 Kg de melado, para o ano de 2014.

Tabela 2 - Cálculo das participações individuais das agroindústrias no mercado e do HHI

\begin{tabular}{ccccc}
\hline Produtores & $\begin{array}{c}\text { Área cultivada } \\
\text { (hectares) }\end{array}$ & $\begin{array}{c}\text { Quantidade de } \\
\text { melado produzida } \\
(\mathrm{kg})\end{array}$ & $\begin{array}{c}\text { Participação } \\
\text { individual no mercado }\end{array}$ & $\begin{array}{c}\text { Quadrado das } \\
\text { participações } \\
\text { individuais }\end{array}$ \\
\hline 1 & 5 & 42.000 & 6,47 & 41,84 \\
2 & 6 & 50.400 & 7,76 & 60,25 \\
3 & 2 & 16.800 & 2,59 & 6,69 \\
4 & 5 & 42.000 & 6,47 & 41,84 \\
5 & 4 & 33.600 & 5,17 & 26,78 \\
6 & 5 & 42.000 & 6,47 & 41,84 \\
7 & 13 & 109.200 & 16,82 & 283,83 \\
8 & 7 & 58.800 & 9,06 & 82 \\
9 & 3 & 25.200 & 3,88 & 15,06 \\
10 & 5 & 42.000 & 6,47 & 41,84 \\
11 & 2,3 & 19.320 & 2,98 & 8,85 \\
12 & 10 & 84.000 & 12,94 & 6,69 \\
13 & 2 & 16.8000 & 2,59 & 41,84 \\
14 & 5 & 42.000 & 6,47 & 15,06 \\
15 & 3 & 25.200 & 3,88 & 880,7773 \\
Total & 77,3 & 649.320 & 100 & - \\
Média & 5,2 & 43.288 & 6,67 & \\
\hline
\end{tabular}

Fonte: elaboração dos autores com base nos dados coletados, 2015.

Mesmo que dois dos produtores se destaquem com uma área plantada de $10 \mathrm{e}$ 13 hectares, significativamente maior que a média de 5,2 hectares, e, consequentemente, na quantidade produzida de melado, já que o cálculo foi realizado a partir 
de uma produtividade média ( $8.400 \mathrm{Kg}$ de melado/hectare), o índice HHI, que resultou no valor de 880,7773, na soma dos quadrados das participações individuais, segundo a definição descrita no método, mostra que o mercado não é concentrado, pois o valor é mais próximo de 0 . Em outras palavras, a estrutura de mercado do melado da agroindústria da cana-de-açúcar, no município de Santo Antônio da Patrulha, é concorrencial, o que determina as condições em que os produtores atuam nesse mercado.

Essas condições significam que os produtores de melado não têm poder sobre a determinação do preço, mesmo que estejam produzindo um dos principais insumos de um produto que possui apelo comercial em Santo Antônio da Patrulha, pois o município é reconhecido regionalmente por sua tradição na produção da rapadura, o que é relevante do ponto de vista da participação do município na caracterização do produto.

Outro resultado que pode ser observado a partir da entrevista aberta com a Emater/RS local é que, ao longo da existência do Programa Puro Engenho, o número de produtores participantes cresceu, no entanto, não houve mudança significativa na área plantada de cada produtor, também foi observada uma maior qualidade do melado, a partir de melhorias no acondicionamento e na armazenagem, o que tem resultado na negociação de contratos de venda com as empresas produtoras de rapadura.

\section{Considerações finais}

O objetivo deste trabalho foi analisar a estrutura de mercado do melado da agroindústria da cana-de-açúcar no município de Santo Antônio da Patrulha. Para isso, foi utilizado o cálculo do índice HHI, a partir dos dados de produção obtidos em entrevistas com os produtores familiares e com a Emater/RS local. Ainda, para contribuir na análise, o referencial teórico mostrou a importância de se conhecer o mercado e a sua concentração, bem como a caracterização e a importância dessa agroindústria para o município e as intenções do Programa Puro Engenho ao envolver o conjunto dos produtores familiares.

$\mathrm{O}$ resultado do índice HHI, obtido a partir do cálculo dos dados relativos à produção de melado estimada pela área cultivada de cana-de-açúcar, considerando uma produtividade média de $8.400 \mathrm{Kg}$ de melado/hectare, foi de 880,7773. Segundo 
a definição descrita no método, que vai de 0 a 10.000, o mercado não é concentrado, ou seja, a estrutura do mercado do melado é concorrencial. Isso determina a forma com que os produtores atuam nesse mercado, desde a menor possibilidade de determinar preço até uma situação adversa em relação às condições colocadas pelas empresas produtoras de rapadura e outros derivados que utilizam o melado como insumo, mesmo o melado sendo um importante insumo, ainda mais quando produzido no município, para caracterizar a rapadura como um produto local, dado o reconhecimento do vínculo cultural e histórico entre de Santo Antônio da Patrulha e esse produto.

O Programa Puro Engenho, que é constituído por um grupo informal de produtores, coordenados pela Emater/RS local, conforme entrevista aberta com a própria Emater/RS, apresentou um número crescente de produtores desde que foi criado. Entre as observações sobre o resultado desse agrupamento, destaca-se que não houve alteração da área plantada por produtor familiar, no entanto, com ajuda da assistência técnica, foi observada uma maior qualidade do melado, a partir de melhorias no acondicionamento e na armazenagem, o que tem resultado na negociação de contratos de venda com as empresas produtoras de rapadura.

Por fim, entre as ações que podem ser identificadas e que podem contribuir para o crescimento do setor e o desenvolvimento da região, pode ser indicada a formalização do grupo que faz parte do Programa Puro Engenho, com o objetivo inicial de ganhar poder de barganha, tanto nas negociações com a indústria da rapadura e outros derivados do melado quanto com os fornecedores de insumos para o cultivo da cana-de-açúcar e equipamento para industrialização do melado. Ainda, é fundamental que esses produtores iniciem um processo de gestão da produção, a partir de um controle dos custos e do que se produz. Para um segundo momento, pode-se sugerir uma gestão profissional que, a partir de uma consolidação do grupo de produtores familiares, poderia pensar em produzir os derivados do melado, com a criação de uma marca própria e a possibilidade de obter certificação como a Denominação de Origem. 


\title{
El mercado de miel de la agroindustria familiar de Santo Antônio da Patrulha, RS
}

\begin{abstract}
Resumen
Santo Antônio da Patrulha, en el estado de Rio Grande do Sul, es un municipio con cerca de 42.220 habitantes. El cultivo de la caña de azúcar, más específicamente la producción del melado, se diversificó en varios productos obtenidos a partir de ese, los cuales llevaron al municipio a ser reconocido por su producción de un dulce, azúcar morena. A partir de esta realidad, el objetivo de la investigación es analizar la estrutura del mercado del melado de la agroindustria familiar para contribuir con el desarrollo del sector y de la región. Los datos se analizaron a partir del índice Herfindhal-Hirschmann Index. El índice encontrado fue de 880.773 , lo que significa que el mercado no está concentrado, indicando que hay competencia entre los productores. Esto lleva a las implicaciones en las condiciones de venta de estos productos en Santo Antônio da Patrulha.

Palabras clave: Concentración de mercado. Agroindustria familiar. Melado.
\end{abstract}

\section{The molasses market of the agribusiness family from Santo Antônio da Patrulha, RS}

\begin{abstract}
Santo Antônio da Patrulha, in the state of Rio Grande do Sul, is a municipality with about 42,220 inhabitants. The sugar cane crop, more specifically the molasses, diversified in the various products obtained from the raw material, which led Santo Antônio da Patrulha to recognition for this production. Based on this reality, the objective of the research is to analyze the market structure of the family agribusiness in order to contribute to the growth of the sector and consequently to the regional development. Data were analized from the Herfindhal-Hirschmann Index. The index found was 880,773 , which means that the market is not concentrated, indicating that there is competition between producers. This leads to implications in the conditions of sale of these products in Santo Antônio da Patrulha. Keywords: Market concentration. Family agribusiness. Molasses.
\end{abstract}

Classificação JEL: R11 


\section{Referências}

BAIN, J. Industrial organization. Berkeley: Wiley Edict, 1968. 678 p.

CONSELHO ADMINISTRATIVO DE DEFESA ECONÔMICA (CADE). Guia para análise de atos de concentração horizontal. 2016. Disponível em: http://www.cade.gov.br/acesso-a-informacao?publicacoes-institucionais/guias_do_Cade/guia-para-analise-de-atos-de-concentração-horizontal.pdf. Acesso em: 02 maio 2016.

EMATER/RS. EMPRESA DE ASSISTÊNCIA TÉCNICA E EXTENSÃO RURAL DO ESTADO DO RIO GRANDE DO SUL. Programa Puro Engenho: Depoimento [dez.2015]. Entrevistador: Ana Mônica Fitz de Oliveira: FURG, 2015. Entrevista concedida ao projeto: O mercado do melado da agroindústria familiar de Santo Antônio da Patrulha - RS.

FARINA, E. Organização industrial no agribusiness. In: ZYLBERSZTAJN, D.; NEVES, M. F. Economia e gestão dos negócios agroalimentares. São Paulo: Pioneira, 2000. p. 39-60.

FEE. FUNDAÇÃO DE ECONOMIA E ESTATÍSTICA SIEGFRIED EMANUEL HEUSER. Corede Metropolitano Delta do Jacuí. 2016. Disponível em: http://www.fee.rs.gov.br/perfilsocioeconomico/coredes/detalhe/?corede=Metropolitano+Delta+do+Jacu\%ED. Acesso em: 12 abr. 2016.

FERREIRA, G.; BARCELLOS, M. Vantagens e desvantagens das alianças estratégicas: uma análise sob a ótica dos agentes da cadeia produtiva da carne bovina. Organizações rurais \& Agroindustriais, Minas Gerais, v. 8, n. 1, p. 117-130, 2006.

GEORGE, K.; JOLL C. Organização industrial: crescimento e mudança estrutural. Rio de Janeiro: Zahar; 1983.

KUPFER, D.; HASENCLEVER, L. Economia industrial: fundamentos teóricos e práticos no Brasil. Rio de Janeiro: Campus, 2002. 424 p.

LABINI, P. Oligopólio e progresso técnico. São Paulo: Forense, 1980. 306 p.

PORTER, M. A vantagem competitiva das nações. Rio de Janeiro: Campus, 1993. 897 p.

POSSAS, M. Estruturas de mercado em oligopólio. São Paulo: Hucitec, 1985.

POSSAS, M.; FAGUNDES, J.; PONDÉ, J. Defesa da concorrência e regulação de setores de infra-estrutura em transição. Revista de Direito Econômico, 1998. Disponível em:http://www. ans.gov.br/portal/upload/forum_saude/forum_bibliografias/regulamentacaodomercado/CC3.pdf. Acesso em: 03 fev. 2015.

POSSAS, M. L. et al. Ensaios sobre economia e direito da concorrência. São Paulo: Singular, 2002. $238 \mathrm{p}$.

SOUZA, M. Concentração industrial em quatro ramos industriais. Revista de Administração de Empresas, São Paulo, v. 20, n. 4, p. 27-43, 1980.

WANDSCHEER,E.;BASTIAN, L. As agroindústrias de derivados de cana-de-açúcar em Santo Antônio da Patrulha - RS. In: ENCONTRO DE ECONOMIA GAÚCHA, 5. Porto Alegre, 2010. Disponível em: http://cdn.fee.tche.br/eeg/5/24.doc. Acesso em: 02 nov. 2015. 